K. LEE, D. L. Silverio, S. TORKER, D. W. ROBBins, F. HAEFFnER, F. W. VAN DER MEI, A. H. HOVEYDA* (BOSTON COLlEGE, CHESTNUT HILl, USA)

Catalytic Enantioselective Addition of Organoboron Reagents to Fluoroketones Controlled by Electrostatic Interactions

Nature Chem. 2016, DOI: 10.1038/nchem. 2523.

\title{
Enantioselective Addition of Organoboron Reagents to Fluoroketones
}

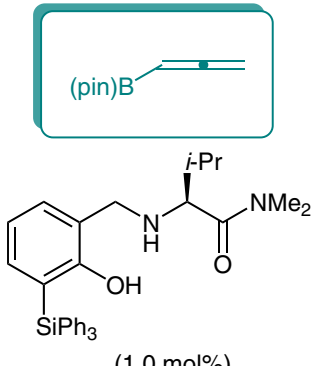

$(1.0 \mathrm{~mol} \%)$

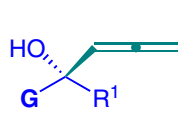

11 examples

$85-98 \%$ yield

(er up to 99:1)

Method 1

$\mathrm{G}=\mathrm{CF}_{3}, \mathrm{C}_{2} \mathrm{~F}_{5}, \mathrm{C}_{3} \mathrm{~F}_{5}$

$\mathrm{R}^{1}=$ various substitutens

$\mathrm{R}^{2}=\mathrm{H}, \mathrm{Me}, \mathrm{Cl}$

Selected examples:

Method 1

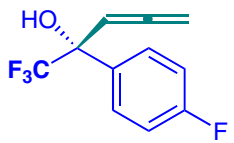

Method 2

$$
\begin{gathered}
87 \% \text { yield } \\
(\mathrm{er}=97.5: 2.5)
\end{gathered}
$$

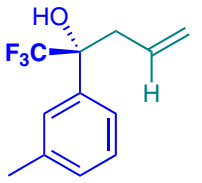

$94 \%$ yield

$(\mathrm{er}=92.5: 7.5)$

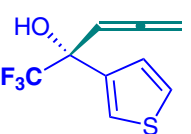

$88 \%$ yield $(\mathrm{er}=99: 1)$

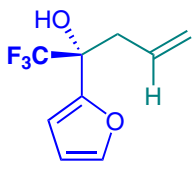

$77 \%$ yield $(\mathrm{er}=90: 10)$

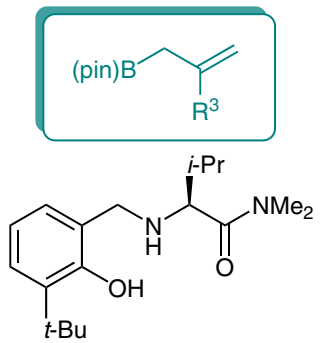

(1.0-2.5 mol\%)

$t$-BuONa (10 mol\%) $\mathrm{MeOH}(1.3$ equiv)

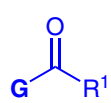

$\mathrm{PhMe}, 22^{\circ} \mathrm{C}, 4 \mathrm{~h}$
Category

Metal-Mediated

Synthesis

\section{Key words}

organoboron reagents

fluoroketones

enantioselectivity

Synfact, then the of the
Significance: Hoveyda and co-workers have developed an efficient catalytic method for the addition of allyl and allenyl organoboron reagents to fluoroketones, leading to trifluoromethyl-substituted tertiary alcohols in up to $98 \%$ yield.

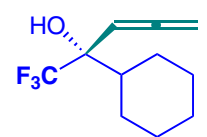

$85 \%$ yield $(\mathrm{er}=94: 6)$

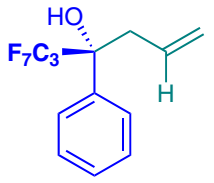

$89 \%$ yield $(\mathrm{er}=96.5: 3.5)$<smiles>C=C[C@@](O)(c1ccccc1)C(F)(F)F</smiles>

$89 \%$ yield $(\mathrm{er}=97: 3)$

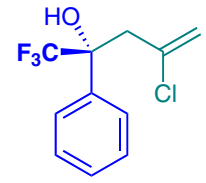

$96 \%$ yield $(\mathrm{er}=96.5: 3.5)$

SYNFACTS Contributors: Paul Knochel, Dorothée Ziegler

Comment: The versatility of the presented method is illustrated in an enantioselective route to the antiparasitic drug fluralaner (Bravecto, Merck). 